\title{
Design-Based Research: Definition, Characteristics, Application and Challenges
}

\author{
Hamed Vaezi* \\ Hossein Karimi Moonaghi** \\ Reyhaneh Golbaf***
}

\begin{abstract}
In recent years medical education has developed dramatically, but lecturers often cite the existence of a gap between theoretical and practical knowledge. In the first decade of the present century, new research methodology named "design-based research $(D B R)^{\prime \prime}$ was developed, which most experts and journals refer to as a fundamental way to make changes in the quality and applicability of studies and educational research as well as to enhance and improve the practice of instruction. The aim of the present study was introducing design-based research and its concepts, features, applications, and challenges. A narrative review was conducted in 2018. For this purpose, authorized English academic database including Web of Science, Science Direct, Google Scholar, international database and library in medical research filed with keywords including "design-based research, definition of DBR, DBR applications, medical education, and DBR challenges" without date limitation until 2018.11.21 were screened. Overall, 68 articles were selected and after careful reading, 21 article with related subjects were selected for material extraction. The conclusion was made that DBR that combines empirical research with design-based theories could be considered as an effective method for understanding quality, time and the cause of the phenomenon of educational innovation in practice. Usually DBR is formed by initial evaluation of a problem that occurs in a particular context, and this assessment continues throughout design and implementation. One of the characteristics of DBR is the guiding team, which includes researchers, professionals, designers, managers, teachers, trainers and others whose expertise and knowledge may in some way help. The application of DBR in webbased training programs is quite evident. The probability of non-returns in short-term projects is one of the main challenges of DBR. Medical education has developed dramatically in recent years, but it has made little progress in promoting innovative research methodologies. DBR can be used as a bridge between theories and practice and provide the basis for close communication between researchers, designers, and participants. By applying sophisticated methods and multiple sources of information, the success rate of an intervention in a particular environment is assessed, which ultimately leads to improved theories.
\end{abstract}

Key words: Design Based research, Define of DBR, DBR Applications, Medical Education, DBR Challenges

\footnotetext{
* Master of Medical Education, Department of Medical Education, School of Medicine, Mashhad University of Medical Sciences, Mashhad, Iran

** Professor، Nursing and Midwifery Care Research Center, Department of Medical Surgical Nursing, School of Nursing and Midwifery, \&

Department of Medical Education, School of Medicine, Mashhad University of Medical Sciences, Mashhad, Iran

*** Master of Medical Education, Department of Medical Education, School of Medicine, Mashhad University of Medical Sciences, Mashhad, Iran.

Corresponding Email: karimih@mums.ac.ir
} 


\section{Introduction}

Medical education has expanded greatly in recent years, so that the number of journals in medical education has been more from the number of researchers in the field, internationally. But the question that arises is: does research in the field of medical education lead to improvements in the application of knowledge? Masters often state the existence of a gap between theoretical knowledge and practical knowledge. According to experts in this field, the existing problem in the research and studies of the medical education field is the lack of development and extension of knowledge frameworks in this field (Dolmans \& Tigelaar, 2012). According to experts in the field of medical education, research that has been carried out in previous years, either has been carried out in some way which has not added new knowledge to this field or some of these studies have not had a suitable theoretical background. The importance of this issue is that, if study and research do not have a suitable theoretical background, it is difficult to understand and explain the factors affecting the research and to explain why an intervention has been effective or ineffective. Educational research should be part of the knowledge and theory structure as well as understanding and dealing with educational problems, because education takes place in complex environments that have many factors affecting it. Educational research should examine how these different factors affect one another and how an intervention works or does not work (Dede, 2005; Dolmans \& Tigelaar, 2012).

Another critique on educational research is that it has little effect on practice. This may be due to various reasons:

- researchers' priorities are often different from the priorities of educational managers and teachers;

- the practical aspect of some studies is not significant;

- the theoretical studies do not follow a special instruction, and this will peak in research based on practice;

- $\quad$ researchers often limit their papers to data collection and analysis instead of presenting the problem and ways of solving it (Dede, 2005).

In the first decade of the current century, a new research method called "design-based research" has emerged. Many scholars and journals have called it a fundamental way for changing in the quality and applicability of educational studies and research as well as increasing and improving the function of education in practice (Anderson \& Shattuck, 2012).

Design-based research emphasizes the link between research and practice, because direct application of the theory on practice is not possible due to the existence of complex relationships between theory and practice. Therefore, researchers, educators and practitioners must work together using DBR in order to identify and resolve problems and gaps and eliminate these distinctions. This approach will focus on research with a periodic cycle of design, application, operation, analysis, and design of new templates (Wang \& Hannafin, 2005). The purpose of this paper is to introduce design-based research, including conceptualizations, features, methodology, applications, and challenges, so that researchers can use this research approach to remove the gap between theoretical knowledge and practical knowledge in the field of education.

\section{Methods}

This study, applying narrative review approach, was held in 2018. A comprehensive review of papers using computer search in reputable English databases such as Web of Science, Science Direct, Google Scholar, international and foreign libraries and databases in the field of medical education was carried out with keywords such as Design Based Research, Define of DBR, DBR Applications, Medical Education, DBR Challenges, without time limit, and until November 21, 2018. In the first step, 107 papers 
which included the mentioned keywords in their titles, were selected and, according to the mastery of the authors in English, the abstracts of these papers were carefully examined. Then, in the second step, 68 papers were selected and studied in more detail with regard to the more subject matter and content validity, content quality, scientific credit, quality, and update the papers. In the third step, the papers were carefully reviewed and a number of papers were excluded from the study process. At the end, 21 papers were selected which were more consistent with the subject and purpose of the study.

\section{Findings}

Definition: In the early 1990s, the definition of 'research design' and, later, in 1992 the term 'experimental design was proposed by Brown, because he believed that research design could remove the gap existing in educational studies and its methodology. Research design was done to understand the learning nature in educational environment and to carry out evaluations that examine educational design based on theories. Since then, various terms such as design experiments, design research, and finally design-based research have been proposed (Dolmans \& Tigelaar, 2012). Other definitions have been mentioned in many papers to express this concept, educational research and knowledge research has been used, but today the term design-based research (DBR) has been accepted (Anderson \& Shattuck, 2012). Design-based research is often described as interventionist or pragmatic in its literature, and like other scientific research, involves identifying, evaluating, applying change and modifying, or intervening to solve a problem (Ford, McNally, \& Ford, 2017).

For readers of such papers, DBR may not be a new method, but just a new term for intervention research, for example, the method by which an executor examines and evaluates his/her educational methods and improvements. However, DBR is not limited to designing, evaluating, and observing whether measures are at the expected level or need to be improved. An important point is that, in addition to the above; one proper DBR also looks at the nature of the complexities of education. The relationship between theory and practice is the most important aspect of the difference of DBR from similar methods. Another point is that DBR uses different methods to understand the factors and their effect, that is, it focuses on both the results and on how to emerge results. In fact, reality-based research can only be done by DBR and other methods. For example, the use of mixed-methods research, in which both quantitative and qualitative methods are applied, is important in design-based research, because they lead to a deep understanding of the results. For researches looking for answers to questions like "How does it work?" and "Why does it work?" is suitable. These methods are also applicable to medical education because they raise our awareness of cases where studies are important and improve our understanding of the subjects under study (Dolmans \& Tigelaar, 2012). According to the authors, DBR, which combines empirical research with theory-based designs, can be a useful way to understand how, when and why the emergence of educational inventions is in practice, as well as DBR in an effort to strengthen learning and create knowledge can be used to help improve human capacity for educational change and reform. DBR is an emerging paradigm for studying and learning the systematic design of educational strategies and tools, and it has been argued that DBR can help create knowledge and expand it, as well as develop and maintain an innovative and active learning environment. For example, the Riser Project, a research program to support the training and learning of the lesson of biology, showed that DBR, in addition to achieving good results in the project, also demonstrated the level of understanding and psychological aspects of students (Collective, 2003). The proper implementation of innovation is a critical factor in improving the performance of education, and research should be aimed at helping teachers and trainers to acquire the knowledge and skills necessary to implement these innovations. However, in the process of developing and implementing innovations, there is often an imbalance between designers and professionals, which makes the implementation of projects in practice insufficiently successful. Design-based research is built on close collaboration between researchers, designers and participants, resulting in more integration and coordination between 
theory and practice in education system. In addition, it is believed that, in order to bring the theories closer to practice in the educational environment, it is necessary to pay more attention to the goals of individuals who are in the learning position, which will result in the promotion of the application of these innovations in a wider environment. This will not be possible unless the design team and specialists participate in planning and designing innovations in the same educational environment (Štemberger \& Cencic, 2016). It should be noted that the implementation of DBR in a real environment and in practice can significantly enhance programs in terms of resources and budgets, since it enables the design team to evaluate its hypotheses in the same real environment and to identify and reject unfavorable events and process (Easterday, Lewis, \& Gerber, 2014).

Therefore, summing up the definitions viewed above, design-based research is a method that is implemented in an experimental and educational environment and its purpose is to develop theories and to create a link between theory and practice. It involves identifying, evaluating, applying changes and modifications, and intervening in the program design process and other steps that are performed periodically with the participation of all stakeholders involved in the study, including instructors, learners, teachers, designers, and researchers.

Discussions about the transformation of theories into practice in the field of education have always been the subject of discussion, and it has been felt that the results of the research are often not sufficiently effective in practice. Given the complexity of teaching and the learning environment mentioned above, it is not reasonable to focus research on the passive publishing of knowledge. Researchers should use it to solve problems in the field of education, and today it is believed that knowledge should be created from practice. In order to improve the education and learning of researchers and professionals, innovations must be used in practice to advance education. Using DBR as a scientific approach through the implementation of multiple data collection and analysis cycles can promote the proper implementation of innovations in schools and universities. It now seems to be the time to advance research-based design in education system (Shah, Ensminger, \& Thier, 2015).

\section{DBR Features}

An important feature of DBR is that it does not occur in an experimental and theoretical environment, but in a real environment where education and practice take place. The second feature is that it relies on the complex nature of training and learning. Therefore, the design is implemented and evaluated in a standardized and natural learning environment, which leads to the identification of new dimensions of problems that the design can rely on. The third feature of DBR is its reliance on theory - it aims to advance theories in the complex educational environment and the factors affecting it. The fourth feature is that in DBR it involves both quantitative and qualitative methods to understand the complex relationships between students and instructors and the tools and content as well as the contradictions in the same relationships. Finally, its fifth feature, which leads to collaborative work among designers, instructors and learners in each levels and expertise, it is designed and evaluated (Collective, 2003; Dolmans \& Tigelaar, 2012).

According to Anderson and Shattuck, these features are accepted for DBR including 1 - The emergence and implementation of it in an educational context and in a real environment that this issue validates our research and assures us that great results can be used in practice. 2 - Designing and focusing on a specific intervention, in the sense that an effective intervention should be able to transfer from the experimental class environment to the real and normal class. 3 - A suitable platform for collaboration between researchers and teachers to overcome the functional problems of education through the accurate creation and evaluation of its environment and texture. 4 - By recording time, requirements, facilities and possibilities researchers can evaluate the achievement of the results and goals of the program. Another point is that in a practical educational environment, the teacher is both a researcher and a teacher at the same time. Studies in this field (Anderson \& Shattuck, 2012; Cole, Purao, Rossi, \& Sein, 
2005; Kuhne \& Quigley, 1997) have shown that teachers often refuse to apply the traditional process of research because of their busy schedules. Also, researchers are not fully aware of the cultural and technical complexities, as well as of the teaching rules of the real classroom to be able to create or discover the effects of interventions. Therefore, the coordination between them can effectively solve problems and defects in the construction, design, intervention, application and evaluation of theories. Another important point is that teachers and researchers are sometimes confused in distinguishing between design-based research and practice- based research, although both have similar patterns. But there is 'reflection' at all steps of DBR, while practice- based research is conducted by teachers, so it lacks the energy, potential and skill of a design team (Anderson \& Shattuck, 2012; Kuhne \& Quigley, 1997).

DBR processes are flexible during application. Schwartz et al. (1999) argued that research design should be flexible, but sustainable with the important principles of learning. In addition, in order to improve the design process, researchers must also be aware of the changes during the design process, so that applying any change in design aspect must be consistent with other aspects of design, and so that the researchers by balancing their roles, should be addressed both design and research and its structural form. The objectivity and validity of DBR are widely increased by methods such as study, expert review, evaluation, case study, interview, retrospective analysis, and by a combination of these methods. The methods may also focus on the needs and thus improve the quality of research. Researchers may use different methods to review and record observations and changes in the classroom environment, while moving toward practicality and effectiveness of the methods. Schwartz also recommended the following principles in DBR. 1 - Support design by research from the very beginning. 2 - Determine the practical goals for the theory and its expansion and follow the program. 3 - Focus on research in real situations which has feedback capabilities. 4 - Work closely with participants. 5 - Follow the research method systematically and purposefully. 6 - Analyze data in retrospective repeatedly. 7 - Improve the design in a developmental way. 8 - Evaluate the extent of generalizability and general ability of design (Wang \& Hannafin, 2005). Usually the start of DBR is formed with an initial evaluation of a problem that occurs in a particular context, and this evaluation continues throughout design and implementation. The DBR team includes researchers, professionals, designers, managers, teachers, trainers, and others whose expertise somewhat may help by sharing their knowledge (Herrington, Reeves, \& Oliver, 2014). Also in DBR, learner-participants and those who are known as program stakeholders are essential along with the specialized team (Russell, Jackson, Krumm, \& Frank, 2013).

\section{DBR Application}

A practical example of design-based research is conducted by Dolmans and Tigelaar (2012) provision and setting up of an educational portfolio to improve the professional performance of teachers in higher education with regard to different educational aspects and the need for communication and the alignment of education and evaluation. This work was fulfilled using multiple methods of collecting data and a combination of quantitative and qualitative methods. In the first step, the Delphi method was first used to collect data, and then meetings were held to examine the theories and their shortcomings. In the second step, evaluations and studies were held in a small group, in order to achieve new dimensions and methods of interventions that were carried out by portfolio. In the third step, teachers' comments, responses and actions were examined and evaluated. Finally, a study was conducted on portfolio evaluation methods and executive criteria to improve its quality.

In Wang and Hannafin (2005) research in the field of tele-education and the use of online services in education, it is stated that the design-based research model contributes to progress in practice and has shown a high potential in this regard. Of course, DBR does not replace other methods, but somehow, with the design and research coverage extends the practice being the context of theory. The design-based research emphasizes collaboration and the coordination between theory and practice, which in this study was able to improve and extend the design and theories of tele-education. Tele-design and research activities can be more 
bilateral than before, and designing educational environments will be combined with the expansion of theories. In DBR, researches are based on the evidence, they cause achieving tangible changes in tele-education, and designers use evidence to improve it. Additionally, DBR provides the basis for creating and studying useful operating methods that their dimensions are not clear yet. Finally, it was argued that design-based research has the potential to build theories that both meet the needs of teachers and improve the educational process and help teachers to understand better tele-education (Wang \& Hannafin, 2005).

In the research by Hege, Kononowicz, and Adler (2017) in the field of training and improving clinical decision-making and diagnoses fields and using virtual patients, the DBR method was used with the aim of designing a system for upgrading tools, details of models, and eventually pushing students to reach a conceptual map for differential diagnosis of patients. During the implementation of the program, the capability of using virtual patients was recorded and reviewed using a primary sample, as well as comments and suggestions of students and professors, and then provided to researchers and authors of the project. Subsequently, a review and revision was carried out during the implementation of the new program, which included displaying new details, the possibilities of advanced search, applying new frameworks and templates, and, in some cases, improving speed and ordering processes with the aim of improving educational conditions and clinical decision making for students (Hege et al., 2017).

A study by Bacon et al. (2015) was conducted with aim of improving students' clinical evaluations during clinical stages, using web-based education. The method of this study implied developing a web-based program called Feed for the Future by using DBR. The research approach focused on designing and researching simultaneously the promotion of technology and its development. In this way, continuous reforms were carried out, taking into account the participants' processes and reflections, and finally, the results of the DBR study were considered as a proper approach to the performance of web-based tools and its development (Bacon et. al., 2017).

In another example, a study by Dornan et al. (2005) was held with the aim of finding a way to improve self-direction training and problem-based learning (PBL) for medical students in a clinical environment by DBR method. The main purpose and method of this study was to design and plan a web-based learning management system that could enhance PBL in students and clarify their clinical purposes for them. In this study, the purposes of the program were monitored step by step according to the feedback, as well as participants involved in the process and supported by the executors. The results of each group were recorded and feedback was evaluated in formative assessment. Finally, it was argued that DBR improved the system, as well as increased persistence and enthusiasm in students (Dornan et al., 2005).

A study by Subramaniam et al. (2015) was carried out with the aim of using DBR to improve adolescent literacy. The method of this study was to use DBR to design, implement, and revise in Hack Health program. They studied on the data collection in the literacy skills and the level of health literacy of participants in Hack Health and related challenges using various tools such as participant observations, surveys, interviews, recording their web activities and also a series of specialized forms. To analyze the data, qualitative and quantitative methods were used. Finally, the results indicated that the improvement and evaluation of these skills and the active collaboration of the participants would ultimately improve the long-term perspective of such projects in society (Subramaniam et al., 2015).

In another example, Koivisto et al. (2018a) conducted research with the aim of promoting and improving clinical competencies and reasoning and creating the necessary competence in clinical environment for nurses. The method of this research was to adopt a DBR method for designing and planning a simulated game, in collaboration with researchers, trainers and students. In the first step of DBR, the principles of design were first extracted from theoretical knowledge and theories, then, in the next step, these principles were evaluated in terms of credibility and validity, then the extracted empirical knowledge 
immediately was carried out in the clinical environment. The results of this study provide the basis for redesigning these projects and the feasibility and use of similar simulated games in the future, and projects aimed at educating and learning clinical reasoning or other similar projects. Authors and researchers of this project described the role of DBR as effective in developing clinical skills in nursing education (Koivisto et al. (2018a).

Another study with the aim of introducing design-based research and its application for the creation of educational models was carried out in collaboration with three universities including VIA in Denmark, Huddersfield in England and Metropolia in Finland. As mentioned, the aim of this study was to introduce DBR for proper design and creation of principles and model of education and development. One of the results of this study was the production of an educational model of NESTLED and its redesigning principles. According to the results, the role of trainers and instructors as facilitators in education is essential. In the study, a large number of researchers and designers and experts in education field were involved to use the DBR method to design and create new learning environments and develop them internationally. The NESTLED program is now used to train nursing instructors to facilitate educational simulation in all three countries involved in the ongoing project, and the tested model can be used to ensure the quality of this educational method at a wider level (Koivisto et al., 2018b).

Another study by Ross, Mitchell, \& Williams (2017) was conducted, which dealt with the factors that increase self-esteem and enhance students' success factors in life. The method used was DBR approach and designing a proper diet and examining its effect on the success of the curriculum and social programs. After the planning of the project, a curriculum improvement evaluation was carried out. The results of statistical tests and data analysis as well as the views of project researchers could provide a useful framework for better evaluation and effective monitoring of the project (Ross, Mitchell, \& Williams, 2017).

\section{DBR challenges}

Although design-based research is rapidly becoming a popular method in educational research, the question is whether DBR is suitable for short-term projects like masters' or PhD. In most references, as well as the opinion of the experts in this field, DBR is a long-term approach that involves several steps of repetition and redesign, development, and revision, and may not be a suitable template for short-term projects because DBR has a number of steps and many cycles in its design and implementation process. The response to the previous question may lie in the response to the question - what is the basis for repeating cycles and time of the project? And how is it determined? (Pool \& Laubscher, 2016). Of course, according to Pool, two studies in PhD degree have been able to successfully implement their study principles and interventions using DBR, given their time constraints (Hakkarainen, 2009).

The disadvantages of design-based research are that it often has no generalizability, since the review has been done for a specific subject and terms and with specific criteria and is only applicable to the given case. Another disadvantage associated with complexity and time-consuming nature of DBR is its high reliance on redesign with testing and improving theories may be neglected. However, some designs focus more on testing or proving theories, and others focus on the application of theories. One should not forget that all these studies use theories to help improve them and seek to respond the question whether these theories are practical (Dolmans \& Tigelaar, 2012). Another criticism of the DBR, for example, deals with the need of research, review, evaluation and redesign. In these cases, the DBR does not specify the number of steps needed to improve design and subsequent evaluations and it is difficult to determine whether the design cycle is already completed or will be completed later. For this reason, confidence in the capability of extending the results to other research will not be certain.

Among these features and concerns, it was found that DBR has features that are the basis for improving educational knowledge and improving experimental research; but the raised question is on what scale DBR can be used or what the issues 
affecting it are. Should it be used in a region, state or country, or globally? And the more important question is whether designbased research should only be applied on a large scale or on a small scale (Anderson \& Shattuck, 2012).

From another perspective, the challenges of DBR are described so that first challenge is related to the methodology, that is, for example, knowing when to modify or continue a method is somewhat difficult, because there is no standard for effect evaluation, and even if it is useful, it is impossible to measure it in other conditions in terms of usefulness. The second challenge deals with the presence of the researcher in the educational classroom, which will lead to people not displaying their normal behavior, or even that a teacher or a professor refuse to apply this method in his / her classroom. The third case is changes in samples, that is, changes in new fields of planning or behavior with participants that may occur at any time. The fourth case is the need for this method to refer to the full data collection on a large scale, which itself requires a lot of time and effort (Wang \& Hannafin, 2005).

\section{Discussion}

In Iran, the use of design-based research is still unrecognized and unconventional, and it may be said to be somewhat degree neglected. It is worth noting that most of the studies conducted in this field (73\%) were held in the United States. Compared to the next countries - the Netherlands and the United Kingdom - where $5 \%$ and $4 \%$ of such research were held, respectively. Also, the number of papers published in this field has reached from less than 20 to about 400 studies in the time range between 2000 and 2010 (Collective, 2003). The results of the studies state that most papers of the DBR field include these concepts in their studies over the past decade. First, design-based research is continuing to expand throughout the world, following the United States' example, and second; most interventions have been in the field of online education and mobile learning technology. Third, DBR projects provide much information, but the exchange of this information is still not high, and the exchange of information should be extended. Fourth, the reference to the important feature of DBR, which is the study, explanation, and modification of theoretical foundations in the process of applying the results practically. Fifth, qualitative analysis on empirical studies has shown that the results are focused on the findings of researchers and on the effect of interventions on participants' and learners' findings. In other words, the focus on both theory and practice have almost existed in all studies. Finally, most studies point to the progress of programs and studies and the coordination between theories and interventions in the educational environment (Anderson \& Shattuck, 2012). A systematic review of the DBR status and position over the past decade has been done by Zheng (2015). In this study, 162 papers related to this field have been reviewed. The demographics of this study showed that DBR was the most widely used and applied in the field of higher education. Also, DBR has also been welcomed in the field of distance learning. In the case of design-based research, most studies were also based on qualitative methods, which is consistent with past opinions by experts in the field that DBR can apply qualitative and descriptive methods. |The data were collected mostly by interviews and questionnaires. In the discussion of educational fields, the most application and use of DBR has been mentioned in the design and construction of technological and computer interventions (Zheng, 2015).

\section{Conclusions}

Medical education has made remarkable progresses over the past years, but it has made little progresses in promoting theories. Medical education studies and research should go toward measuring, evaluating and improving theories to explain the factors of failure or success, which should, of course, be done under certain conditions. DBR can be used to make a bridge and way between 
theory and practice and provide the basis for close communication between researchers, designers and participants, until using complex methods and multiple sources of information; it evaluates the success of an intervention in a particular environment and situations, and ultimately lead to improve theories. Design based research, to the same extent that leads to the improvement of theories, needs more effort and attention than other aspects of the study.

\section{Acknowledgment}

This article is part of the approved project of the Research Vice-President of Mashhad University of Medical Sciences (ID: 941455$)$. So, the authors would like to thank the Research Vice-President and all the professors who have helped them in this study, despite the lack of time. We thank the Department of Medical Education in particular, Dr. Ali Emadzadeh, and all members of the faculty of medicine, for the guidance and advice on improving the quality of this paper.

\section{References:}

Anderson, T. \& Shattuck, J. (2012). Design-based research: A decade of progress in education research? Educational Researcher, 41(1), 16-25.

Bacon, R., Williams, L. T., Grealish, L., \& Jamieson, M. (2015). Competency-Based Assessment for Clinical Supervisors: Design-Based Research on a Web-Delivered Program. JMIR Research Protocols, 4(1), e26.

Brown, A. L. (1992). Design experiments: Theoretical and methodological challenges in creating complex interventions in classroom settings. The Journal of the Learning Sciences, 2(2), 141-178.

Cole, R., Purao, S., Rossi, M., \& Sein, M. (2005). Being proactive: where action research meets design research. ICIS 2005 $\begin{array}{llllll}\text { Proceedings, } & \text { 27. } & \text { Retrieved } & \text { September } & 1, & 2019\end{array}$ https://www.researchgate.net/publication/221599527_Being_Proactive_Where_Action_Research_Meets_Design_Research

Collective, D.-B. R. (2003). Design-based research: An emerging paradigm for educational inquiry. Educational Researcher, 32(1), 5-8.

Dede, C. (2005). Why design-based research is both important and difficult. Educational Technology, 45(1), 5-8.

Dolmans, D.H., \& Tigelaar, D. (2012). Building bridges between theory and practice in medical education using a design-based research approach: AMEE Guide No. 60. Medical Teacher, 34(1), 1-10.

Dornan, T., Hadfield, J., Brown, M., Boshuizen, H., \& Scherpbier, A. (2005). How can medical students learn in a self-directed way in the clinical environment? Design-based research. Medical Education, 39(4), 356-364.

Easterday, M.W., Lewis, D.R., \& Gerber, E.M. (2014). Design-based research process: Problems, phases, and applications. $17^{\text {th }}$ International Conference of the Learning Sciences: Learning and Becominfg in Practice, 317-324. Boulder, USA.

Ford, C., McNally, D., \& Ford, K. (2017). Using design-based research in higher education innovation. Online Learning, 21(3), 5067.

Hakkarainen, P. (2009). Designing and implementing a PBL course on educational digital video production: Lessons learned from a design-based research. Educational Technology Research and Development, 57(2), 211-228. 
Hege, I., Kononowicz, A.A., \& Adler, M. (2017). A clinical reasoning tool for virtual patients: design-based research study. JMIR Medical Education, 3(2), e21.

Herrington, J., Reeves, T.C., \& Oliver, R. (2014). Authentic learning environments. In Spector, J.M., Merrill, M.D., Elen, J., \& Bishop, M.J. (Eds.). Handbook of Research on Educational Communications and Technology, 401-412. New York: Springer.

Koivisto, J.-M., Haavisto, E., Niemi, H., Haho, P., Nylund, S., \& Multisilta, J. (2018a). Design principles for simulation games for learning clinical reasoning: A design-based research approach. Nurse Education Today, 60, 114-120.

Koivisto, J.-M., Hannula, L., Bøje, R. B., Prescott, S., Bland, A., Rekola, L., \& Haho, P. (2018b). Design-based research in designing the model for educating simulation facilitators. Nurse Education in Practice, 29, 206-211.

Kuhne, G. W., \& Quigley, B. A. (1997). Understanding and using action research in practice settings. New Directions for Adult and Continuing Education, 73, 23-40.

Pool, J. \& Laubscher, D. (2016). Design-based research: is this a suitable methodology for short-term projects? Educational Media International, 53(1), 42-52.

Ross, L., Mitchell, L., \& Williams, L. (2017). Is it possible to enhance the confidence of student dietitians prior to professional placements? A design-based research model. Journal of Human Mutrition and Dietetics, 30(5), 588-595.

Russell, J.L., Jackson, K., Krumm, A.E., \& Frank, K.A. (2013). Theories and research methodologies for design-based implementation research: Examples from four cases. Yearbook of the National Society for the Study of Education, 112(2), 157-191.

Shah, J.K., Ensminger, D.C., \& Thier, K. (2015). The time for design-based research is right and right now. Mid-Western Educational Researcher, 27(2), 152-171.

Štemberger, T. \& Cencic, M. (2016). Design based research: The way of developing and implementing. World Journal on Educational Technology: Current Issues, 8(3), 180-189.

Subramaniam, M., Jean, B. S., Taylor, N.G., Kodama, C., Follman, R., \& Casciotti, D. (2015). Bit by bit: Using design-based research to improve the health literacy of adolescents. JMIR Research Protocols, 4(2), e62.

Schwartz, D.L., Lin, X., Brophy, S., \& Bransford, J.D. (1999). Toward the development of flexibility adaptive instructional designs. In C. M. Reigeluth (Ed.), Instructional-Design Theories and Models, vol. II, 183 -213). Mahwah, NJ: Lawrence Erlbaum.

Wang, F. \& Hannafin, M.J. (2005). Design-based research and technology-enhanced learning environments. Educational Technology Research and Development, 53(4), 5-23.

Zheng, L. (2015). A systematic literature review of design-based research from 2004 to 2013. Journal of Computers in Education, 2(4), 399-420. 